\section{UJMM

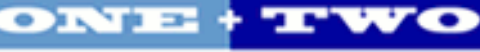

Volume 3 | 2011 Spring

\section{Undergraduate Journal of Mathematical}

Modeling: One + Two

2011

\title{
Sizing of an Ammonia Discharge Tank
}

Tuliagenda Beckfords

University of South Florida

\author{
Advisors: \\ Brian Curtin, Mathematics and Statistics \\ Scott Campbell, Chemical \& Biomedical Engineering \\ Problem Suggested By: Scott Campbell
}

Follow this and additional works at: https://digitalcommons.usf.edu/ujmm

Part of the Mathematics Commons

UJMM is an open access journal, free to authors and readers, and relies on your support: Donate Now

\section{Recommended Citation}

Beckfords, Tuliagenda (2011) "Sizing of an Ammonia Discharge Tank," Undergraduate Journal of Mathematical Modeling: One + Two: Vol. 3: Iss. 2, Article 10.

DOI: http://dx.doi.org/10.5038/2326-3652.3.2.10

Available at: https://digitalcommons.usf.edu/ujmm/vol3/iss2/10 


\title{
Sizing of an Ammonia Discharge Tank
}

\begin{abstract}
Phosphate companies use well-stirred tanks to regulate the concentration of ammonia they discharge via their wastewater, preventing ammonia spikes from exceeding the cap set by the Environmental Protection Agency. This report discusses the methods used to determine the minimum possible volume of the tank required to regulate wastewater discharge. With this information, it was determined that the use of a stirring tank is an efficient and cost effective way to regulate ammonia discharge. Based on these results many other companies may use this method to decrease the negative effects of ammonia on the environment.
\end{abstract}

\section{Keywords}

Environmental Protection, Ammonia Concentrations, Stirring Tanks

Creative Commons License

(c) (i) (3)

This work is licensed under a Creative Commons Attribution-Noncommercial-Share Alike 4.0 License. 


\section{TABLE OF CONTENTS}

Problem Statement

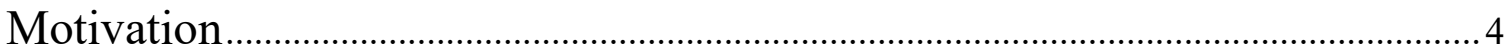

Mathematical Description and Solution Approach ................................................5

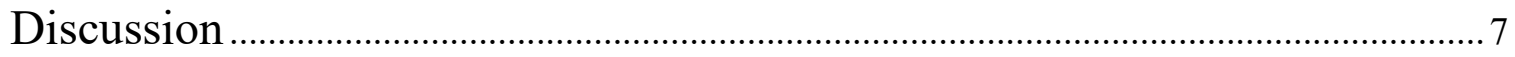

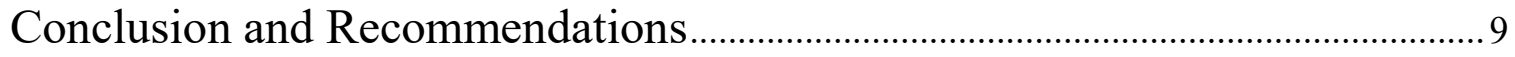

Nomenclature

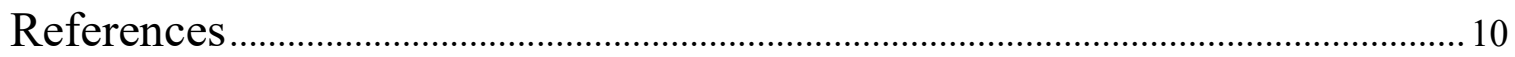




\section{PROBLEM STATEMENT}

A phosphate company discharges wastewater containing some ammonia into a nearby river. New EPA regulations have put a cap of 100 ppm maximum ( $1 \mathrm{ppm}$ is $1 \mathrm{mg} / \mathrm{L})$ on the level of ammonia that can be discharged to the river. The company estimates that, on average, the pollutant levels are below the maximum, but occasionally there are spikes in the concentration that goes above the EPA regulation. An engineer suggested putting in a well-stirred holding tank as shown in the Figure 1 to minimize the fluctuations and keep the output level of ammonia below the cap.

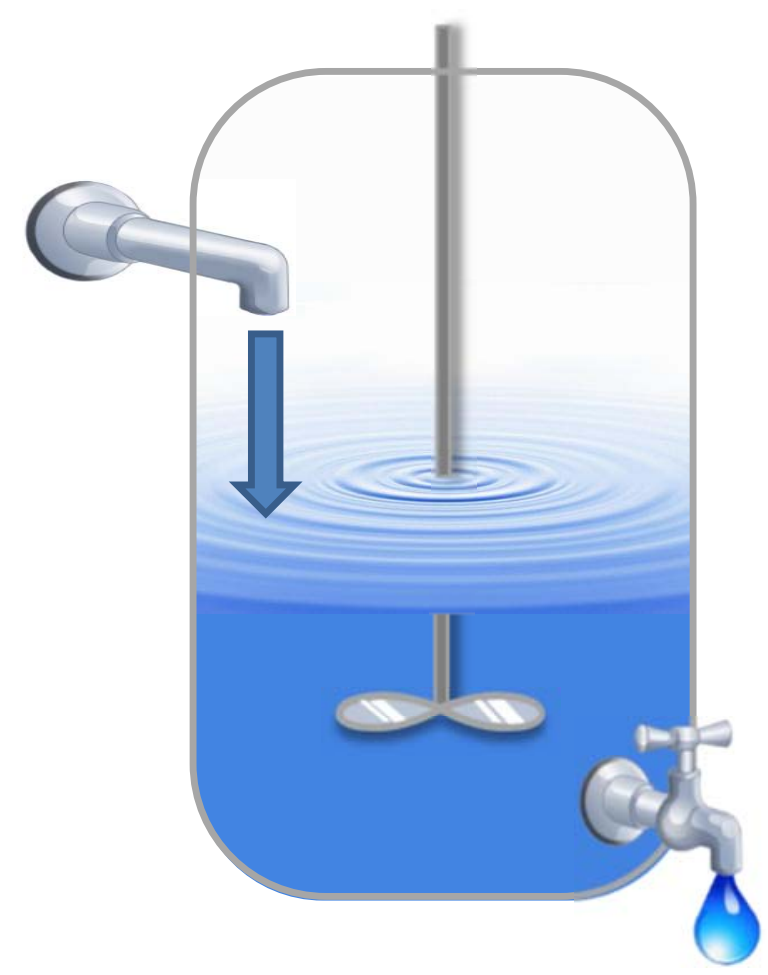

Figure 1: Well-stirred tank mixing the ammonia wastewater before it enters the river.
We wish to determine the volume $V$ of the holding tank such that the concentration of the effluent from the tank does not exceed the EPA cap.

Suppose that the average flow rate $Q$ of the wastewater is $25 \mathrm{~L} / \mathrm{s}$. The average concentration $C_{\text {in }}$ of ammonia is $40 \mathrm{ppm}$, but occasional spikes of 400 ppm have been observed. A worst-case scenario is shown in Figure 2.

Based on this worst case

scenario, what tank volume $V$ would be required to keep the maximum output concentration $C_{\text {out }}$ below the EPA regulation? 


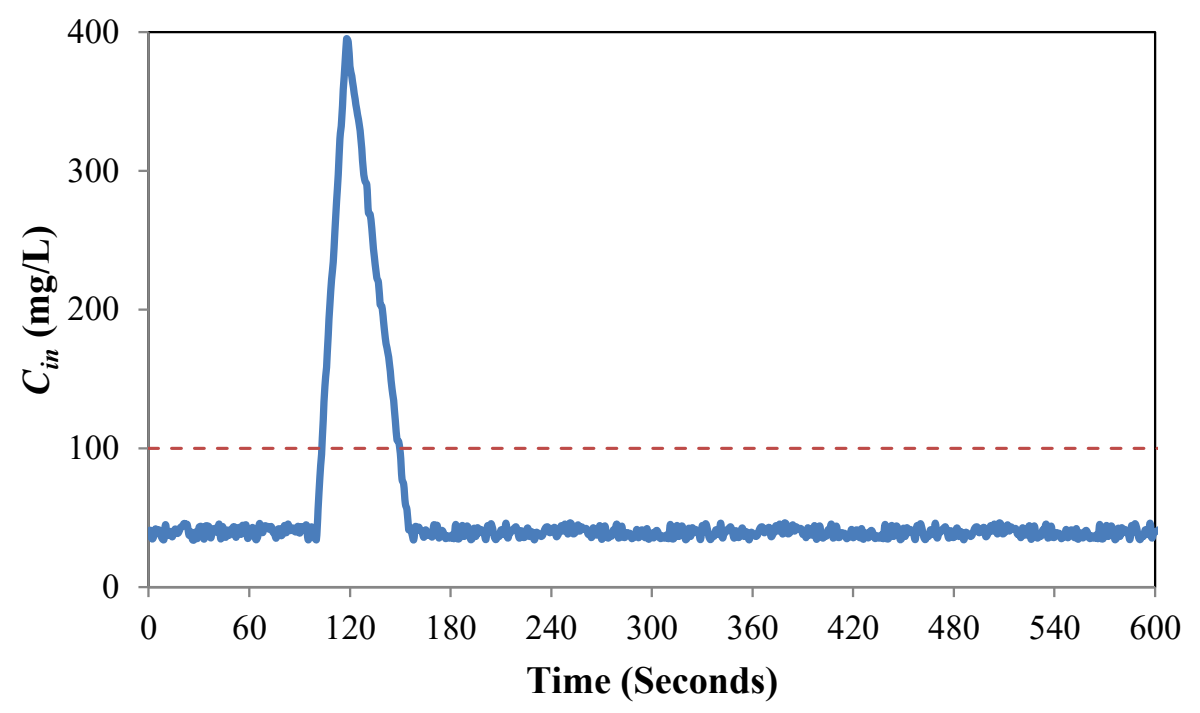

Figure 2: Recorded concentration of ammonia (solid line) in the wastewater of a phosphate plant. Without the use of a stirring tank, these concentrations will exceed the EPA's cap (dashed line).

\section{MOTIVATION}

Ammonia is an important source of nitrogen, which is important to sustain animal and plant life. However, the release of ammonia in aquatic environments can have dire consequences on the animals and plants living in that environment. Fish and other animals living in water which ammonia is released into may be poisoned resulting in reduced reproductive capacity and reduced growth of the young of some species (Alan).

Ammonia also exerts a direct biochemical oxygen demand on the water it is released into, as the dissolved oxygen in the water is consumed during the oxidation of ammonia which results in moderate to severe depressions of dissolved oxygen concentrations. Lowered dissolved oxygen concentrations are associated with a reduction in the diversity of aquatic species and death of some fish (Environmental Impacts: Ammona). Eutrophication, or nutrient over enrichment of water ammonia is released into, can also occur. This can lead to troublesome algae blooms (Environmental Impacts: Ammona). 
Ammonia is often released into the environment from various industries including phosphate companies such as the one given in this problem. In order to prevent the severe environmental effects such as those listed above from occurring it is important to regulate the concentration of ammonia released by these industries to a level deemed safe to the environment by the United States Environmental Protection Agency.

In this problem a well-stirred tank is proposed as a solution to this environmental concern. It is therefore very important to determine the volume of the tank such that the concentration of ammonia released into the environment does not exceed the EPA cap.

\section{MATHEMATICAL DESCRIPTION AND SOLUTION APPROACH}

We can begin by writing a mass balance formula for ammonia. The rate of accumulation of ammonia in the tank is equal to the rate of ammonia entering the tank less the rate of ammonia leaving the tank. This can be expressed by the equation

$$
\frac{d}{d t}[C V]=Q\left(C_{i n}-C\right)
$$

where $C_{\text {in }}$ is the concentration of the ammonia entering the tank, $C$ is the concentration of the ammonia in the tank (equivalent to $C_{\text {out }}$, the concentration of the ammonia flowing out of the tank), $Q=25 \mathrm{~L} / \mathrm{s}$ is the volumetric flow rate of the stream and $V$ is the volume of the tank.

The volume of the tank $V$ is constant over time so

$$
C^{\prime}(t)=\frac{d C}{d t}=\frac{Q}{V}\left(C_{\text {in }}-C\right)
$$

gives an expression for the rate of change of concentration of the ammonia in the wastewater tank with respect to time. 
The ideal method of solving a problem of this kind would be through the use of differential equations; however we favor a numerical approach. In this case the Euler method, gives a good approximation of the solution to (2).

Recall that

$$
C^{\prime}(t)=\lim _{\Delta t \rightarrow 0} \frac{C(t+\Delta t)-C(t)}{\Delta t}
$$

so

$$
C(t+\Delta t) \approx C^{\prime}(t) \Delta t+C(t)
$$

for $\Delta t$ close to zero. If $\Delta t$ is fixed, we can let $t_{i+1}=t_{i}+\Delta t$ and (5) becomes

$$
C\left(t_{i+1}\right)=C^{\prime}\left(t_{i}\right) \Delta t+C\left(t_{i}\right)
$$

In this problem we know that the average concentration of ammonia flowing into the tank was $40 \mathrm{ppm}$ so we estimate the tank to contain an initial concentration of $40 \mathrm{ppm}$, i.e. $C(0)=40$.

With the concentrations depicted in Figure 2, Excel was used to implement Euler's method and calculate the ammonia concentration flowing out of the tank for a fixed volume $V$. For each volume, a graph depicting the peak concentrations (Figure 3 and Figure 4) were plotted to easily determine if the EPA's cap was exceeded. The tank volume was then systematically changed until the optimal volume was determined. 


\section{DISCUSSION}

The description of this project is to determine the volume of a holding tank such that the concentration of the effluent from the tank does not exceed the EPA cap. In order to minimize costs and maximize the efficiency of the phosphate company, we find the minimum volume of the tank which fulfills the EPA's requirements.

Through the use of Excel, several estimates of the volume were made until it was found that a volume of 4,000 liters was sufficient to meet the EPA's rule. However, upon examination of Figure 3 it is clear that the minimum volume possible for the holding tank was not met.

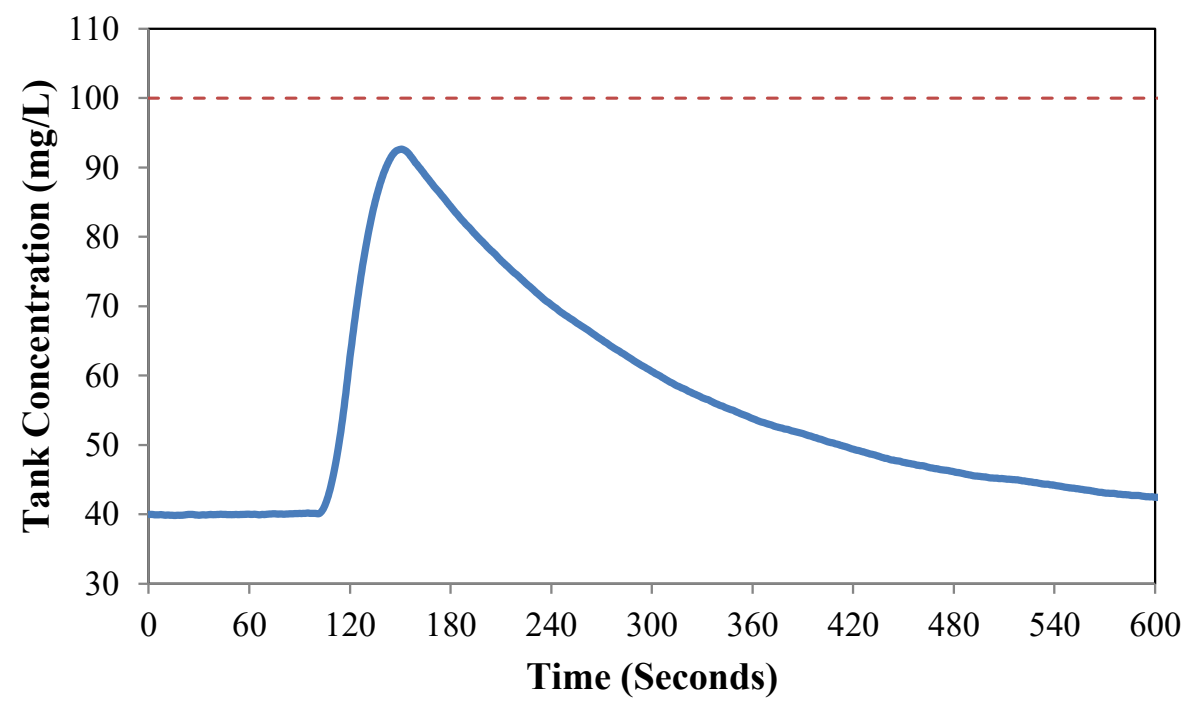

Figure 3: Concentration of ammonia (solid line) leaving a 4,000 liter wastewater tank for the river and the EPA's cap on ammonia discharge (dashed line).

The volume was then systematically decreased until it was found that the tank could have a minimum volume of 3,418.36 liters (903.04 gallons) without violating the cap (Figure 4). 


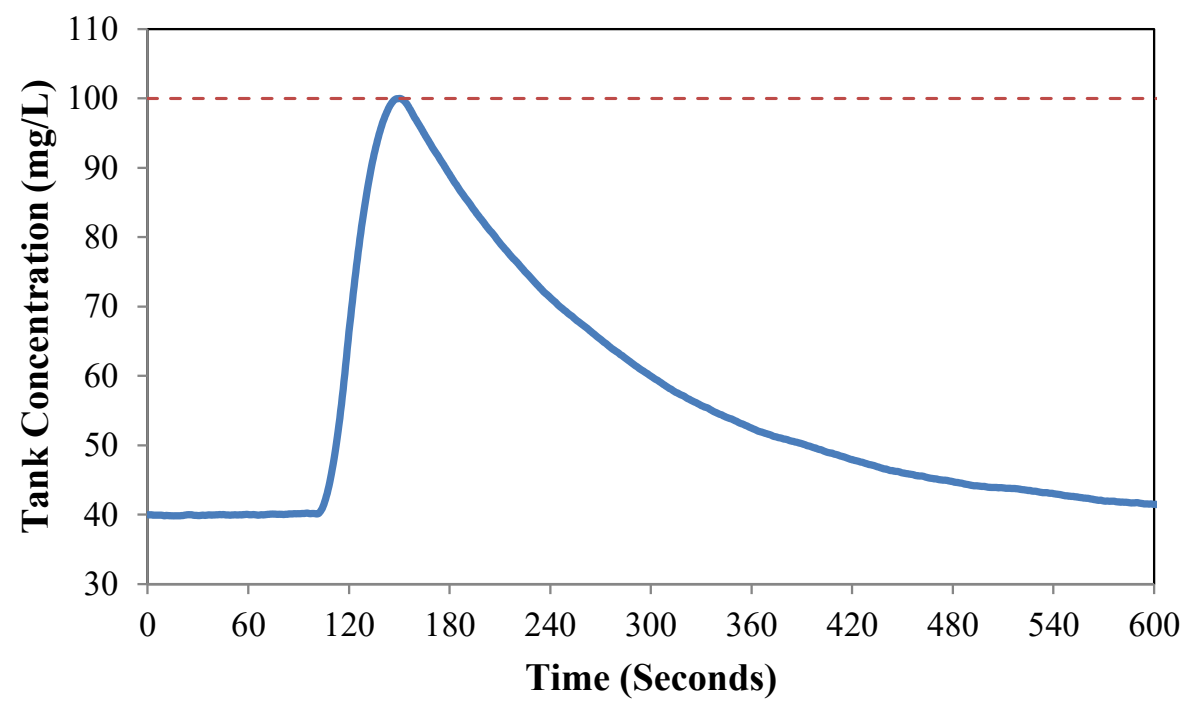

Figure 4: Concentration of ammonia (solid line) leaving the optimal 3,419 liter wastewater tank without violating the EPA's cap (dashed line).

A typical 1,000-gallon vertical stirring tank will be shaped like a cylinder having a diameter of 64" and height 80" (Dimension Guides). This means that this is a reasonably sized tank which would not be considerably expensive to build or purchase. With a relatively inexpensive way of controlling their ammonia output, the phosphate company would more than likely accept an engineer's proposal of using a well-stirred tank to comply with the EPA's standards.

This project showed that the environmental damage associated with high concentrations of ammonia in wastewater can be cheaply avoided. Stirring tanks are an inexpensive way for companies to protect the environment. Furthermore, the limited financial risk involved with this solution may compel companies to decrease the concentrations of their ammonia output well below the EPA cap resulting in safer and cleaner aquatic environments. 


\section{CONCLUSION AND RECOMMENDATIONS}

Euler's method was used to solve the ammonia concentration mass balance formula. From this we found that a stirring tank must be at least 3418.36 liters (903.04 gallons) to avoid discharging water containing more than 100ppm of ammonia into the river. Since 1000-gallon stirring tanks are an industry standard and relatively inexpensive, we conclude that the engineer's suggestion will likely be accepted by the phosphate company.

Often times companies use chemicals to handle their wastewater output, but this can prove to be expensive and time consuming. In light of the information obtained from this project, mechanical methods of dealing such well-stirred tank seem like a viable alternative to the use of chemicals. We believe that many companies would become more actively involved in decreasing their wastewater output given this cheaper and effective solution. Practical solutions to industrial problems result in a cleaner and safer environment. 


\section{NOMENCLATURE}

\begin{tabular}{|clc|}
\hline Symbol & Description & Units \\
\hline$C$ & Concentration of ammonia in the stirring tank & $\mathrm{mg} / \mathrm{L}$ \\
\hline$C_{\text {in }}$ & Concentration of ammonia entering the stirring tank & $\mathrm{mg} / \mathrm{L}$ \\
$C_{\text {out }}$ & Concentration of ammonia leaving the stirring tank & $\mathrm{mg} / \mathrm{L}$ \\
\hline$Q$ & Volumetric Flow Rate & $\mathrm{L} / \mathrm{s}$ \\
\hline$V$ & Tank Volume & $\mathrm{L}$ \\
\hline$t$ & Time & $\mathrm{s}$ \\
\hline
\end{tabular}

\section{REFERENCES}

Alan, Robert. Lewis' Dictionary of Toxicology. Informa HealthCare, 1998.

Dimension Guides. Dimensions of a 1000 Gallon Tank. 23 April 2011

$<$ http://www.dimensionsguide.com/dimensions-of-a-1000-gallon-tank/>.

"Environmental Impacts: Ammona." 10 September 2009. U.S. Environmental Protection Agency. April $2011<\mathrm{http}: / /$ www.epa.gov/agriculture/ag101/impactammonia.html>. 